\title{
COMO ASTRONAUTAS CEGOS: DIREITOS HUMANOS E EFETIVIDADE NO BRASIL
}

\author{
Viviane Freitas Perdigão Lima ${ }^{1}$ \\ Renata Caroline Pereira Reis Mendes ${ }^{2}$
}

\section{RESUMO}

Analisa os Direitos Humanos e sua efetividade no Brasil. Utiliza a pesquisa bibliográfica, documental e jurisprudencial. Aborda a construção histórica e multidimensionalidade dos Direitos Humanos. Apresenta a base conceitual e jurídica que sustenta tais direitos no contexto internacional e nacional. Discute os problemas da implementação destes e indica a urgência em romper com o distanciamento entre a amplitude de enunciação de direitos e sua implementação prática. Aponta a cultura em Direitos Humanos como um caminho para a libertação de indivíduos e a construção de sujeitos de direitos.

Palavras-chave: Direitos humanos. Enunciação. Efetividade. Educação em Direitos Humanos. Multidimensionalidade

\section{AS BLIND ASTRONAUTS: HUMAN RIGHTS AND EFFECTIVENESS IN BRAZIL}

\begin{abstract}
It analyzes Human Rights and its effectiveness in Brazil. It uses bibliographical, documentary and jurisprudential research. It addresses the historical construction and multidimensionality of Human Rights. It presents the conceptual and legal basis for these rights in the international and national context. It discusses the problems of their implementation and indicates the urgency of breaking away from the gap between the extent of rights enunciation and its practical implementation. It points to culture in Human Rights as a way for the liberation of individuals and the construction of subjects of rights.
\end{abstract}

Keywords: Human rights. Enunciation. Effectiveness. Education in Human Rights. Multidimensionality

\section{INTRODUÇÃO}

Vive-se em um contexto de intensas transformações (sociais, políticas, econômicas, morais, etc.). Palavras como globalização, pós-modernidade, sociedade virtual, desenvolvimento, movimentos sociais, democracia, por exemplo, insurgem ideias, concepções e desejos. Mas também desafios, na medida em que questões complexas são (ou precisam ser) suscitadas e enfrentadas, sob múltiplos enfoques.

\footnotetext{
${ }^{1}$ Mestra em Direito pelo programa Direito e Instituições do Sistema de Justiça da Universidade Federal do Maranhão (UFMA). Professora da Universidade Estadual do Maranhão e Universidade Ceuma. Advogada. http://lattes.cnpq.br/7955567083507463

${ }^{2}$ Mestra em Cultura e Sociedade pela Universidade Federal do Maranhão. Professora do Instituto Florence de Ensino Superior (IFES). Advogada. http://lattes.cnpq.br/4649996800991390.
} 
Nessa perspectiva, o mundo inseriu em sua pauta de discussões as questões relacionadas aos Direitos Humanos, sobretudo no período posterior à Segunda Guerra Mundial. Afinal, nesse quadro histórico é que grandes violações à condição do ser humano foram efetivadas, sobretudo pela imposição de regimes ditatoriais, autárquicos e totalitários.

Desde então, a comunidade global organizou-se com vistas a traçar metas, no intuito de resguardar a vida, o respeito e a dignidade humana, criando-se um complexo documental, com valor jurídico protetivo.

É oportuno ressaltar que muitas nações, como o Brasil, no âmbito interno, passaram a adotar recomendações oriundas da Declaração Universal dos Direitos Humanos (DUDH), da Organização das Nações Unidas (ONU), em sua legislação, consagrando e enunciando direitos, de forma a refutar práticas desrespeitosas a estes.

A comemoração aos 70 (setenta) anos da referida declaração e a crença de que é apropriado refletir sobre os avanços e retrocessos experimentados nesse período foi o que suscitou inquietação para a pesquisa.

Nesse interim, a presente investigação pretende ocupar-se especificamente com os direitos humanos-fundamentais, com ênfase ao cenário brasileiro. O intuito, portanto, é de apresentar que ainda há muito a conquistar-se, uma vez que o arcabouço teórico enunciado é amplo, porém a sua efetivação não se satisfaz.

Parte-se do seguinte questionamento: qual a situação dos Direitos Humanos no Brasil? Os enunciados construídos e firmados acompanham e materializam sua efetivação material?

Para o estudo, utilizou-se a pesquisa bibliográfica, com vistas a articular a construção conceitual de seu referencial teórico, ocasião em que se desenvolveu a seleção, reunião e a organização de autores que tratam dos Direitos Humanos.

Este, tem como base o pós-positivismo jurídico, concebendo, assim, que os Direitos Humanos são um todo que se estabelece a partir da reunião entre norma, princípios e valores, tal qual a concepção proposta por Bobbio (2004), Bonavides (2016), Comparato (2007), Lynn Hunt (2009).

Dito isto, esta investigação propõe-se a discutir a construção histórica, teórica e multidimensional dos Direitos Humanos. Em seguida, ilustra-se como o país concebe e decide acerca de situações práticas envolvendo a temática, apresentando-se casos de repercussão 
geral. Ao passo em que, discute-se alternativas para a efetivação desses direitos nacionalmente

Por acreditar que se trata de uma temática atual e intrigante, não se pretende esgotar a discussão, mas iniciar e partilhar informações para estudos posteriores.

\section{DIREITOS HUMANOS: aspectos conceituais, filosóficos e formativos}

Abordar as questões acerca da construção histórico-conceitual dos Direitos Humanos constitui o propósito central deste capítulo. Afinal, estes não surgiram como um dado pronto e acabado (ARENDT, 1979).

Portanto, para a compreensão e dimensionalidade que envolve a estes e para perseguir o objetivo aqui pleiteado, de reflexão e direcionamento, faz-se necessário enfatizar a evolução e a concepção contemporânea sobre o tema.

Ao tratar da invenção dos Direitos Humanos, Lynn Hunt (2009) indica que a enunciação destes em documentos formais tornou-se indispensável para a sua proteção. Entretanto, há que se falar que, apesar de apresentar uma fundamentação hodierna, a construção de sua ideia esteve presente e desenvolveu-se lado-a-lado da concepção dos direitos em geral.

Logo, ocorre a publicação de direitos que os seres humanos de forma inquestionável, em razão de sua característica e condição humana, já possuíam (ou pelo menos deveriam possuir).

O jusnaturalismo é uma das correntes que retrata os direitos humanos atribuindo a estes uma existência vinda da lei divina, da natureza e da razão. Lembo (2007) assevera que, por essa concepção, o Direito Natural é visto como posto por Deus.

De outro turno, pautando-se na lei, o juspositivismo direciona-se a uma visão avalorativa, pautada na racionalidade, cientificidade e técnica jurídica. Ou seja, o que deve pautar e ser obedecido pelo aplicador do direito.

O risco da proposição dessa visão mostra-se para o temor que é capaz de instalar, uma vez que pode servir de legitimação de ações abusivas, tal qual o que se deu com o fascismo e o nazismo, cujos efeitos a história tratou de registrar.

Pugliuca (2010) considera que estes seriam criados e legitimados pela lei, a depender da vontade política legislativa. De modo que são, por essa configuração, válidos mediante a concessão e garantia institucional do Estado. 
Enquanto, teóricos, como Lembo (2007) defendem a sobreposição de uma ou outra visão para a proteção de tais direitos. Há, de outro modo, quem veja na união de ambas o caminho para a sua efetivação por meio da aliança entre um aspecto social e a lei (Pugliuca, 2010).

Nessa esteira, destaca-se o posicionamento de Noberto Bobbio (2004). Este associa a construção dos direitos do homem a inversão da concepção com que a humanidade passa a conceber o cidadão e o Estado.

A sua afirmação ocorre da movimentação de sistemas internos e jurídicos de nações, a citar as colônias inglesas, para posteriormente alcançar uma preocupação global. Dessa forma, teorias e bases filosóficas embasaram esse processo.

Da teoria contratualista, desenvolvida por Hobbes, Locke e Rousseau, por exemplo, extrai-se a legitimação da autoridade política que se funda por meio de um acordo, entendido como o acordo entre vontades, em que se estabelece a comunidade política e se instaura o estado civil. Do entendimento desta, os direitos naturais tornaram-se oponíveis (STRECK et al, 2014), sendo atribuição estatal a responsabilidade pela organização social e proteção humana.

Na percepção foucaultiana (2008), o direito natural e a sua teoria estão relacionadas a um arcabouço de direitos capazes de oposição ao poder soberano. Nessa linha, por sua construção cultural, precede ao direito positivo. Este, por sua vez, convalida-se por intermédio da lei e dos costumes, adequando-se ao caráter particular de cada povo.

O pacto associativo de Hobbes (1651) faz a menção ao surgimento do Estado e da sociedade civil. Sua validação é dada por meio da abertura de um caráter particular (a liberdade) em troca da obtenção da segurança e bem-estar social, mantida por uma autoridade reguladora, mediada pela ideia e manutenção da ordem.

Depreende-se do "Segundo Tratado sobre o governo civil" de Locke (2003) a valoração dada à propriedade. Indica-se que a sua expressão de liberdade, bens e vida. Não se contrapôs à escravidão, justificando-a através de uma realização justa. Para Hunt (2009) o poder monárquico e absoluta é fundamental para a autoridade e os sujeitos de direito são concebidos limitadamente.

Já Rousseau (2001) defendeu que a igualdade humana e a condição de liberdade é possível apenas pela livre vontade, dada de forma consciente. O que seria possível de ser alcançado pela defesa de direitos naturais postos como inalienáveis e por meio da República. 
A noção de coletividade é redimensionada e expande-se no sentido da civilidade. Gonçalves (2006, p. 35) pondera que:

[...] a ideia de contrato é diferente, haja vista que, no pacto, foi introduzida a ideia do nós [...]. Com efeito o Contrato Social, em Rousseau, pode ser entendido como um pacto ajustado por todos os indivíduos que transferiram todos os direitos para um ente que não estaria fora do nós (grifos da autora).

É válido frisar que os Direitos Humanos não alcançam uma definição uma, seu formato e conteúdo compreende lutas de origem política e ideológica. Nesse sentido, Bobbio (2004) afirma que estes devem ser vistos como históricos, relativos, imprescritíveis, irrenunciáveis e invioláveis.

A perspectiva de análise é múltipla, abrangendo aspectos éticos, filosóficos, históricos, políticos, culturais. De modo que a denominação para se referir a estes não é uníssona. Desde os séculos XVII termos como Direitos Naturais, Direitos do Homem, Direitos Civis, por exemplo, foram empregados.

$\mathrm{Na}$ concepção moderna, tal qual assenta Bonavides (2016) com fulcro no póspositivismo, sugere-se a abertura da lei aos valores e princípios, uma vez que estes adquiriram reconhecimento, equiparando-se a força ideológica que empregam e a recomendando a observância de ambos na análise de casos concretos.

\section{CONSTRUÇÃO HISTÓRICA E MULTIDIMENSIONALIDADE DOS DIREITOS HUMANOS}

A construção e afirmação dos Direitos Humanos e a sua reunião em documentos foram imprescindíveis para fundamentar eventos históricos impulsionadores do seu reconhecimento.

A Bill of Rights, elaborada pelo Parlamento inglês, em 1689, contou com a assinatura de Guilherme de Orange e é considerada como um marco para a inauguração de normas limitativas ao poderio da Coroa e à certificação de direitos naturais individuais.

Ao condensar a Revolução Glorioso, teve o caráter de pôr fim ao estado absolutista monárquico por ali, tendo valorado a supremacia parlamentar, e possibilitando as atividades da burguesia em ascensão. Seus regramentos dirigiam-se à liberdade privada e a vida (COMPARATO, 2007).

Nos Estados Unidos, a independência das treze colônias deu gênese a que é considerado como a forma inovadora de constitucionalismo federativo no período moderno. 
Instaurou-se uma assembleia democrática, legitimou-se a soberania popular, considerando-se a construção norte-americana formada por cidadãos legalmente livres e iguais.

Seu valor político (COMPARATO, 2007) assenta-se no fato de tratar-se da legitimidade da soberania popular, com o estabelecimento de direitos de maneira igualitária, sem considerar-se distinções de cunho sexual, religioso, cultural, ou social.

Amoldam-se como cartas fundamentais cuja pretensão passava pela emancipação dos indivíduos em face do Estado, da família e das entidades religiosas. Sua base filosófica pautou-se em Locke, Montesquieu e Rousseau.

A relevância da Declaração de Direitos da Virgínia, de 1776, tem seu fundamento na validação dada aos direitos inatos e individuais e da sobreposição destes em face do Estado. Enunciou garantias judiciais, propôs a separação de poderes e ideias de liberdade na religião e na imprensa. De acordo com Ferreira Filho (2009), inspirou as declarações de direito que vieram posteriormente.

Na França, a revolução Francesa de 1789, contrapôs-se ao sistema feudal e aristocrático, apresentou a reestruturação sociopolítica e cuidou em fundamentar as ideias presentes em no novo mundo, cujas bases remontam à liberdade, igualdade e fraternidade.

Para Ferreira Filho (2009), a reivindicar direitos naturais universais, individuais, imprescritíveis, inalienáveis, a Declaração dos Direitos do Homem e do Cidadão pregou a liberdade e isonomia, tendo feito referência ao Cidadão (participação política e limitação estatal) e ao Homem (alcance e direção universal).

A Declaração de Direitos da Constituição de 1791 passou a enfrentar preocupações para além do campo individual. Direitos sociais, como a oferta da educação gratuita, se apresentam.

Amparada nas ideias de Montesquieu, na separação e controle de poder, a Constituição de 1795 apresenta a universalidade cidadã, trazendo deveres voltados a estes, alertando sob o risco da prática do abuso de poder por seus detentores.

A ideia de trabalho, nacionalismo, liberdade, o compromisso com valores democráticos, a civilização, o progresso, dentre outros aspectos, a Constituição Francesa de 1848, apresentou um desenho de uma preocupação com o direito laboral.

Para Comparato (2007), a Convenção de Genebra, de 1864, voltou a sua preocupação para as vítimas da guerra, tantos os soldados quantos os civis, trazendo questões como o direito da guerra e da paz. 
Destaca-se a relevância da Constituição Mexicana, de 1917, como a primeira a promover, ao lado dos direitos políticos e das liberdades individuais, os direitos trabalhistas à classe de direitos fundamentais.

A Constituição de Weimar, de 1919, emerge no século XIX estrutura-se em torno de um valor estrutural, de cunho democrático-social, cuja elaboração que envolve o positivismo ideológico.

A Organização das Nações Unidas firma-se no século XX, após o contexto destruidor que se figurou após da Segunda Guerra Mundial. Sua relevância paira sobre a chamada para a conscientização e urgência de colaboração para que o mundo buscasse a dignidade humana.

Nesse contexto, a expressão Direitos Humanos se consagra e a proclamação de um documento de caráter universal, com pretensão abrangente, uniforme e extenso forma um organismo e espírito protetivo e cooperativo de preocupação internacional, com vistas a oporse as formas de violação anteriormente experimentadas.

A Declaração Universal de Direitos Humanos, de 1948, apresentou princípios fundamentais e simbolizou a representação do gênero humanos, desconsiderando-se critérios excludentes em razão de diferenças particulares, elucidando valores comuns a todas as nações. Separar a concepção de homem e cidadão já não se mostrava plausível.

Para ratificar e consolidar definitivamente tais direitos (civis, políticos, econômicos, sociais e culturais), a Declaração e o Programa de Ação de Viena, de 1993, foi anunciada. Os direitos à paz, solidariedade, desenvolvimento paz e pertinentes ao meio ambiente entram para o círculo de proteção.

Frisa-se que a configuração atual da Declaração Universal não engessa direitos definitivamente. Ao revés, a ideia versada é a de que estes são mutáveis, podendo ser ampliados, porém não restritivos e excludentes.

Portanto, vislumbra-se a igualdade e a dignidade e proporcionou um sentimento político internacional, que contou com a adesão do Brasil, propiciando o estabelecimento de medidas internacionais voltadas para a eliminação da discriminação racial, contra a mulher, contra a tortura, dentre outros.

Ademais, serviu para instruir os sistemas protetivos regionais (europeu, africano e americano), além de inspirar a constituição de múltiplos países. Toma-se a democracia como 
fundamento para possibilitar essa implantação. Afinal, os ditames propostos servem de instrumento para empoderar a população.

Nesse contexto, os Direitos Humanos são considerados sob o viés de uma multidimensionalidade, tal qual empregado por Sarlet (2012), em razão da complementaridade e multiplicidade que não permite que sejam pensados e concebidos de maneira isolada, posto que são indivisíveis.

Adotando-se a visão defendida por Bonavides (2016), considera-se a percepção de cinco dimensões de direitos, sem prejuízo da existência de outros e novas que possam a surgir.

A primeira dimensão associa-se aos ideais de liberdade, do século XVIII, firmandose em relação aos direitos de caráter civil e político, atendendo aos anseios da burguesia. Refere-se, portanto, a liberdade e a regulação de direitos pertinentes à democracia e direitos políticos.

A segunda dimensão diz respeito aos anseios sociais, culturais, econômicos e coletivos suscitados pelo século XIX, no contexto industrial. O Estado que se desenha é visto como garantista e responsável por condições mínimas de aspectos como saúde, habitação, educação, renda e alimentação.

Por sua vez, a terceira dimensão relacionam-se com o transindividual, dirigindo-se a toda a espécie humana, ao lado do sentimento solidário global que se constrói, sendo frutos da globalização e da ideia de sociedade fraterna.

Na quarta dimensão encontram-se direitos voltados para a consolidação de uma sociedade aberta para os ventos do povir, firmando-se na democracia, no pluralismo jurídico e no direito à informação, ocasionados pela globalização.

Enquanto que os direitos de quinta dimensão são pertinentes à paz, condição sine qua non para a sobrevivência da espécie humana e condicionante da democracia participativa. Extraindo-se tais preceitos dos direitos da fraternidade.

Feitas essas necessárias considerações, passa-se a avaliação da situação e dificuldade de sua efetivação no contexto brasileiro.

\section{ENTRE A CEGUEIRA E A EFETIVIDADE: por uma cultura de direitos humanos no Brasil}

"A minha tristeza é a do astronauta cego". (Mia Couto) 
Uma vez conhecida aspectos pertinentes à construção dos Direitos Humanos no mundo, ressalta-se a ambição que a discussão e temática exige. Ora, o contexto da América Latina passou a experimentar a democracia e o cerne de questões pertinentes a tais direitos enfaticamente nos anos 80. No caso brasileiro, a Constituição Federal da República de 1988 teve esse condão.

Desde então, implementou-se uma série de institutos que se convém intitular de Direitos Humanos Fundamentais. Sua importância se dá a partir das lutas sociais instaladas, posicionadas contrariamente ao regime político ditatorial presente naquele contexto histórico.

Dessa forma, atribui-se aos anos 2000 a característica inaugural da era dos Direitos Humanos Fundamentais brasileira. A materialização desse período deu-se com o cuidado dado ao título II, da Carta Magna, em 1988, e da preocupação com direitos de caráter individual, coletivo, social, nacional e políticos ali configurados.

Considera-se que o artigo $5^{\circ}$, do texto constitucional, apresenta um rol meramente exemplificativo de direitos, em razão do reconhecimento da cláusula de abertura. É este o posicionamento defendido pelo Supremo Tribunal Federal (STF), na ocasião da apreciação e julgamento da Ação Direita de Inconstitucionalidade de número 939-DF.

Falar em Direitos Humanos Fundamentais significa, de acordo com a doutrina majoritária e com a legislação nacional, pautar condições necessárias para a manutenção da vida e para assegurar os direitos individuais, bem como a proteção das instituições democraticamente construídas.

Canotilho (2002, p. 369) pondera que

[...] direitos fundamentais são os direitos do homem, jurídico institucionalmente garantidos e limitados espacio-temporalmente. [...] os direitos fundamentais seriam os direitos objectivamente vigentes numa ordem jurídica concreta. [...] Função de prestação social, os direitos a prestações significam, em sentido estrito, direito do particular a obter algo através do Estado (saúde, educação, segurança social).

Nesse sentido, pelo menos formalmente, direitos dessa natureza são enunciados. De modo, que de acordo com o sistema protetivo instaurado a característica de cláusula pétrea tem sido atribuída a estes. O que significa dizer que a sua exclusão ou supressão não se faz possível.

Entretanto, apesar de toda a gama assecuratória há quem considere que a implantação efetiva destes se faz prejudicada. Atribui-se a esta dificuldade o processo 
construtivo/afirmativo com o qual este se deu. $\mathrm{O}$ que se justificaria por uma democracia de baixa intensidade, critério que gera uma realidade de não-cidadãos (SANTOS, 2003).

Posto que, neste modelo hegemônico neoliberal, a cidadania ${ }^{3}$ é bloqueada por mecanismos de exclusão social e política, onde a população é chamada para o posicionamento de decisões irrelevantes, limitando-se ao voto, representando uma verdadeira fraude democrática.

Nesse contexto, não é raro que seja necessário que as pessoas precisem utilizar-se da prestação jurisdicional para que questões de direitos sejam observadas, questionadas. É o que se vê, por exemplo, quando se necessita buscar o Poder Judiciário para assegurar uma vaga de criança em creche e pré-escola, quando o direito à educação é violado.

Nesse sentido, apresenta-se o posicionamento do Supremo Tribunal Federal, no Recurso Extraordinário com Agravo $n^{\circ}$. 63.9337, no qual decretou-se a obrigatoriedade da matrícula nas proximidades da residência do jurisdicionado:

EMENTA: CRIANÇA DE ATÉ CINCO ANOS DE IDADE - ATENDIMENTO EM CRECHE E EM PRÉ-ESCOLA - SENTENÇA QUE OBRIGA O MUNICÍPIO DE SÃO PAULO A MATRICULAR CRIANÇAS EM UNIDADES DE ENSINO INFANTIL PRÓXIMAS DE SUA RESIDÊNCIA OU DO ENDEREÇO DE TRABALHO DE SEUS RESPONSÁVEIS LEGAIS, SOB PENA DE MULTA DIÁRIA POR CRIANÇA NÃO ATENDIDA - LEGITIMIDADE JURÍDICA DA UTILIZAÇÃO DAS “ASTREINTES" CONTRA O PODER PÚBLICO DOUTRINA - JURISPRUDÊNCIA - OBRIGAÇÃO ESTATAL DE RESPEITAR OS DIREITOS DAS CRIANÇAS - EDUCAÇÃO INFANTIL - DIREITO ASSEGURADO PELO PRÓPRIO TEXTO CONSTITUCIONAL (CF, ART. 208, IV, NA REDAÇÃO DADA PELA EC No 53/2006) - COMPREENSÃO GLOBAL DO DIREITO CONSTITUCIONAL À EDUCAÇÃO - DEVER JURÍDICO CUJA EXECUÇÃO SE IMPÕE AO PODER PÚBLICO, NOTADAMENTE AO MUNICÍPIO (CF, ART. 211, § $2^{\circ}$ ) - LEGITIMIDADE CONSTITUCIONAL DA INTERVENÇÃO DO PODER JUDICIÁRIO EM CASO DE OMISSÃO ESTATAL NA IMPLEMENTAÇÃO DE POLÍTICAS PÚBLICAS PREVISTAS NA CONSTITUIÇÃO - INOCORRÊNCIA DE TRANSGRESSÃO AO POSTULADO DA SEPARAÇÃO DE PODERES - PROTEÇÃO JUDICIAL DE DIREITOS SOCIAIS, ESCASSEZ DE RECURSOS E A QUESTÃO DAS "ESCOLHAS TRÁGICAS" - RESERVA DO POSSÍVEL, MÍNIMO EXISTENCIAL, DIGNIDADE DA PESSOA HUMANA E VEDAÇÃO DO RETROCESSO SOCIAL - PRETENDIDA EXONERAÇÃO DO ENCARGO CONSTITUCIONAL POR EFEITO DE SUPERVENIÊNCIA DE NOVA REALIDADE FÁTICA QUESTÃO QUE SEQUER FOI SUSCITADA NAS RAZÕES DE RECURSO EXTRAORDINÁRIO -PRINCÍPIO "JURA NOVIT CURIA" - INVOCAÇÃO EM SEDE DE APELO EXTREMO - IMPOSSIBILIDADE - RECURSO DE AGRAVO IMPROVIDO. POLÍTICAS PÚBLICAS, OMISSÃO ESTATAL

\footnotetext{
${ }^{3}$ Entende-se por cidadania como o direito de ter direitos, tal qual proposto por Hannah Arendt (1979). Por meio dessa compreensão concebe-se esta categoria como pertinente a capacidade que os indivíduos possuem para participar de espaços públicos, percebendo seus direitos e deveres jurídico-civis, combatendo-se a reinstalação de regimes totalitários.
}

Revista de Direitos Humanos e Efetividade | e-ISSN: 2526-0022 | Salvador | v. 4 | n. 1 | p. 152 - 168 
INJUSTIFICÁVEL E INTERVENÇÃO CONCRETIZADORA DO PODER JUDICIÁRIO EM TEMA DE EDUCAÇÃO INFANTIL: POSSIBILIDADE CONSTITUCIONAL. [...] (BRASIL, 2011).

Ou ainda quando se busca atendimento médico, internação, tratamento de saúde essencial para a manutenção do direito à saúde. Como se vê do julgado do STF, no Recurso Extraordinário $\mathrm{n}^{\circ} 855.178$, in verbis:

Direito à saúde. Tratamento médico. Responsabilidade solidária dos entes federados. Repercussão geral reconhecida. Reafirmação de jurisprudência. $O$ tratamento médico adequado aos necessitados se insere no rol dos deveres do Estado, porquanto responsabilidade solidária dos entes federados. O polo passivo pode ser composto por qualquer um deles, isoladamente, ou conjuntamente (BRASIL, 2015).

Em um outro aspecto, a segurança pública também é objeto de solicitação junto ao Poder Judiciário, em razão de medidas e políticas não desenvolvidas e solicitadas pela coletividade. Como retrata o decisum constante do Recurso Extraordinário no 559.646:

APELAÇÃO CÍVEL. AÇÃO CÍVIL PÚBLICA. DIREITO À SEGURANÇA. DIREITO FUNDAMENTAL E SOCIAL. Pretensão do Ministério Público objetivando ver o município compelido a abster-se de realizar evento esportivo no Estádio Municipal de Álvaro de Carvalho, até que se comprovem as necessárias e adequadas condições de segurança. Sentença de procedência na origem. Inconformismo do réu. Descabimento. Inteligência dos arts. $5^{\circ}$ e $6^{\circ}$, caput, da CF/88. Direito a segurança é prerrogativa constitucional indisponível, garantido mediante a implementação de políticas públicas, impondo ao Estado a obrigação de criar condições objetivas que possibilitem o efetivo acesso a tal serviço (BRASIL, 2015).

Nessa conjuntura, para que haja a relação real entre o que é dado, posto e o que é observado, desenvolvido e cumprido é indispensável que cidadãos sejam igualmente construídos. Tal configuração é possível a partir da conscientização de indivíduos, no que tange aos seus direitos e deveres, perante a sociedade e o Estado.

Não é cabível, para tanto, que continue a se perpetuar a construção de pessoas que possuem muito mais deveres, que direitos, sobretudo sociais, como a realidade pátria apresenta, justificando, inclusive, a implementação/disponibilidade destes no mercado capitalista, dado pelo modelo econômico posto pelo neoliberalismo.

Dessa situação, aponta-se a implementação de políticas públicas de enfrentamento a todas as formas de violência, o combate ao desemprego e a pobreza. Romper com os interesses de uma minoria e fortalecer movimentos da sociedade civil é um mecanismo de estímulo aos novos atores sociais. 
Já não cabe, parafraseando Mia Couto, a permanência do estado de cegueira. De nada vale atribuir-se valores e estabelecerem-se direitos sem que condições de execução sejam postas à serviço da população.

Nesse contexto, é que uma cultura em/para os Direitos Humanos faz-se essencial e urgente, de forma a afetar os comportamentos, os processos, as práticas e as mentalidades individuais e coletivas. A aliança entre o estrutural e o campo existencial é o caminho.

Escrivão Filho et al (2016) propõe que se dê voz, vez e ouvidos às movimentações populares, aos trabalhadores, a advocacia popular, a mulher, ao público LGTB. Nessa perspectiva, o Direito Achado Na Rua levanta-se como um campo voltado para buscar na expressão da realidade a identificação, construção e interação entre as normas e os anseios sociais.

O que seria possibilitado por intermédio de assessorias, de educação jurídica e atendimento popular, por meio do diálogo, do exercício de assentimento de denúncia, do direito de expressão e da perseguição a uma existência com dignidade humana.

A pós-modernidade concebe o indivíduo como um ser que é historicamente construído, detentor de uma capacidade de formar, mudar, transformar-se e até mesmo extinguir-se (HALL, 2015).

A educação é, nesse contexto, pressuposto e condição para o exercício da cidadania, tendo o condão de capacitar o indivíduo na condição de sujeito, consciente de si e do outro, de seus deveres e direitos, centro das lutas sociais (TOURAINE, 2006).

Por esse viés, é necessário que as pessoas reconheçam a sua existência e história própria, ao mesmo passo em que conceba os outros "tão legítimos quanto nós, seres sociais como nós, a quem devemos respeitar, despojando-nos de nossos preconceitos e projeções de nossos próprios fantasmas" (AGUIRRE, 2007).

Falar, portanto, em trazer luz para a dimensão proposta perpassa pela Educação em Direitos Humanos (EDH). Quer dizer, significa estimular a retirada da cegueira que o desconhecimento e a ignorância ocasionam.

Nessa perspectiva, Meintjes (2007, p. 122) considera a EDH

[...] como pleno exercício da cidadania requer que cada grupo-alvo esteja capacitado para dar início ao processo de aquisição de conhecimentos e de consciência crítica necessário para compreender e questionar padrões opressores de organização social, política e econômica. 
Como se vê é preciso pisar o freio e reconhecer que a transformação precisa passar pelos aparelhos governamentais, mas também pela experiência e conscientização de cada um. Uma vez que os Direitos Humanos não estão (ou não deveriam) habitar os pensamentos, mas sim as atitudes concretas.

De modo que muito já se percorreu no contexto de afirmação e reconstrução de direitos, uma vez que se saiu de um estado de penumbra quase que total. Mas, diante da configuração histórica, política e cultural atual ainda há muito a se conquistar no contexto brasileiro (e global).

\section{CONSIDERAÇÕES FINAIS}

O estudo em apreço buscou fazer um apanhado histórico, conceitual, ético e documental acerca dos Direitos Humanos com vistas a apresentar o contexto de afirmação e construção que o envolve.

Pontua a visão contratualista e a ponderação da teoria proposta por Locke, Rousseau e Hobbes, além de Foucalt nesse processo. Pontuando-se a legitimidade e autoridade política em face de um acordo/pacto/contrato estabelecido junto à sociedade.

Observou-se que a preocupação com o tema povoa a mente humana desde os períodos remotos. Porém, a preocupação com a sua enunciação se firma, sobretudo no contexto imediatamente ao período que sucede a Segunda Grande Guerra Mundial.

A preocupação que insurgiu naquele momento, conforme buscou-se demonstrar, voltava-se para reunir e pensar os Direitos Humanos, diante dos horrores experimentados no período, em razão dos efeitos desastrosos que esta deixou.

Mostrou-se que os Direitos Humanos se propuseram a embater perseguições, violências, ao mesmo passo em que se voltou para restringir o poder estatal e resguardar direitos, estabelecendo-se a dignidade humana.

Ocupou-se em demonstrar que a nomenclatura utilizada para designar esses direitos foi construída de forma histórica, estando associada, portanto, aos referenciais éticos que lhe serviu de base.

É possível vislumbrar as questões globais e locais, que fundaram documentos importantes, tratados, convenções, pactos no contexto mundial, e a configuração constitucional pátria. 
Considera-se que abordar os Direitos Humanos significa considerá-los como um campo aberto, amplo e possível de transformações e reflexões. Afinal, trata-se de direitos históricos, cujo caráter passou de uma preocupação individual para o social, coletivo e difuso.

É possível ver nestes um instrumento possibilitador de uma vida que seja justa, livre, igualitária e livre. O que vê enseja em uma multidimensionalidade de direitos, postos simultaneamente de maneira independente e associada.

A Constituição de 1988 inaugurou as garantias e Direitos Humanos Fundamentais no Brasil, com a pretensão de instaurar a democracia e a cidadania, refletindo-se acerca de temas de interesse individual, nacional, político, social.

Para o embasamento teórico e metodológico da pesquisa, realizou-se um levantamento teórico, histórico, bibliográfico, documental e jurisprudencial, traçando-se as características, os preceitos e dispostos em autores e documentos que reúnem o assunto.

Demonstrou-se que entre a cegueira e a luz efetiva das realizações, no capo material, ainda há um caminho a ser cruzado. Em razão de que a existência e previsão legal tem feito referência as proteções postas, ao mesmo passo em que o seu alcance necessita de ações a serem desenvolvidas no campo das políticas públicas, da educação, da cultura e do afastamento de uma visão limitada dos indivíduos.

Por outro lado, em razão dessa configuração, a busca pelo Poder Judiciário tem sido um dos meios que a população brasileira tem se utilizado para tentar implementar o que o texto constitucional apresenta, levando o Poder Público a realizar ações silenciadas.

Acredita-se que a busca junto aos movimentos populares, a oitiva e a voz da população e de seus anseios é outra possibilidade para possibilitar essa materialização. Afinal, a garantia de direitos não deve permear apenas os liames e interesses de uma parte ínfima e restrita da população.

Outrossim, proporcionar uma Educação em/para os Direitos Humanos concretiza e sintetiza o que pode ser feito para o cruzamento dessa travessia. Posto que, por meio desta, sujeitos de direitos são desenhados.

Destaca-se, entretanto, que a difusão dos direitos humanos em uma sociedade em que direitos têm sido privados, retirados, ameaçados mostra-se um verdadeiro e grandioso desafio.

De outro turno, não se pretende finalizar a discussão proposta, mas semear e contribuir com o debate, a fim de que caminhos possam ser traçados e vendas sejam retiradas 
para que um dia se alcance a visão clara e real, sem distinção entre o que é posto e o que é dado.

\section{REFERÊNCIAS}

AGUIRRE, Luiz Perez. Educar para os direitos humanos: o grande desafio contemporâneo. $2007 . \quad$ Disponível em: <http://www.dhnet.org.br/educar/redeedh/bib/aguirre.htm>, acessado em 10. Jan. 2017

ARENDT, Hannah. As origens do totalitarismo - Antissemitismo, Imperialismo, Totalitarismo. Trad. Roberto Raposo. Rio de Janeiro, 1979. Disponível em: <http://www.dhnet.org.br/direitos/anthist/marcos/hdh_arendt_origens_totalitarismo.pdf>. Acesso em: 20. Ago. 2017.

BOBBIO, Norberto. A era dos direitos. Rio de Janeiro: Campus, 2004.

BONAVIDES, Paulo. Curso de direito constitucional. 31 a ed. São Paulo: Malheiros, 2016

BRASIL. Constituição Federal da República Federativa do Brasil, 1988. Disponível em: <http://www.planalto.gov.br/ccivil_03/Constituicao/Constituicao.htm>. Acesso em: 15. fev. 2017.

Supremo Tribunal Federal. Recurso Extraordinário com Agravo nº 639337 AgR,

Relator (a): Min. Celso de Mello, Segunda Turma, julgado em 23/08/2011, DJe177, Divulgação 14/09/2011, Brasília, DF, 15 set. 2011. Disponível em:

<http://www.stf.jus.br/portal/jurisprudencia/visualizarEmenta.asp?s1=000179240\&ba se=baseAcordaos $>$. Acesso em 28. ago. 2017.

Supremo Tribunal Federal. Recurso Extraordinário no 855.178 RG/Sergipe, Relator (a): Min. Luiz Fux, julgado em 05/03/2015, Brasília, DF, DJe 16 mar. 2015. Disponível em: $<$ http://redir.stf.jus.br/paginadorpub/paginador.jsp?docTP=TP\&docID=8015671 >. Acesso em 28. ago. 2017.

Supremo Tribunal Federal. Acórdão RE 559.646-AgR - $2^{\mathrm{a}} \mathrm{T}-$ Rel. Ellen Gracie $-\mathrm{j}$. 07/06/2011). Sentença mantida. Recurso não provido. (TJ-SP - APL:

00055764120098260201 SP 0005576-41.2009.8.26.0201, Relator: Djalma Lofrano Filho, Data de Julgamento: 05/08/2015, $13^{\text {a }}$ Câmara de Direito Público, Data de Publicação: DJ 12/08/2015. Disponível em:

$<$ http://redir.stf.jus.br/paginadorpub/paginador.jsp?docTP=AC\&docID=624471>. Acesso 25. Jan. 2017.

CANOTILHO, José Joaquim Gomes. Direito constitucional e teoria da constituição. $5^{\text {a }}$ Ed. Coimbra - Portugal: Livraria Almedina, 2002.

COMPARATO, Fabio Konder. A afirmação histórica dos Direitos Humanos. 5. ed. São Paulo: Saraiva: 2007. 
ESCRIVÃO FILHO, Antonio; SOUSA JUNIOR, José Geraldo de. Para um debate teóricoconceitual e político sobre os direitos humanos. Belo Horizonte: Editora D’Plácido, 2016.

FERREIRA FILHO, Manoel, 1934. Gonçalves. Direitos humanos fundamentais. 11. ed. rev. e aum. São Paulo: Saraiva, 2009.

FOUCAULT, Michel. Nascimento da biopolítica: curso dado no Collège de France (19781979. Edição estabelecida por Michel Senellart; sob direção de François Ewald e Alessandro Fontana; tradução Eduardo Brandão; revisão de tradução Claudia Berliner. São Paulo: Martins Fontes, 2008.

GONÇALVES, Cláudia Maria da Costa. Direitos fundamentais sociais: releituras de uma constituição dirigente. Curitiba: Juruá, 2006.

HALL, Stuart. A identidade cultural na pós-modernidade. 12. ed. Tradução: Tomaz da Silva, Guacira Lopes Louro. Rio de Janeiro: Lamparina, 2015.

HOBBES, Thomas. Leviatã. Tradução de: João Paulo Monteiro e Maria Beatriz Nizza da Silva. 1651. Disponível em:

<http://www.dhnet.org.br/direitos/anthist/marcos/hdh_thomas_hobbes_leviatan.pdf >. Acesso: 05. fev. 2017.

HUNT, Lynn. A invenção dos direitos humanos; uma história. Tradução Rosaura Eichenberg. São Paulo: Companhia das Letras, 2009.

LEMBO, C. A pessoa: seus direitos. Barueri/SP: Manole, 2007.

LOCKE, John. Segundo Tratado sobre o governo. São Paulo: Martin Claret, 2003

MEINTJES, Garth. Educação em Direitos Humanos para o pleno exercício da cidadania: repercussões na Pedagogia. In: Educação em Direitos Humanos para o Século XXI. Andreopoulos, Geroge J.; CLAUDE, Richard Pierre (orgs). PINHEIRO, Ana Luiza (trad). São Paulo: Editora da Universidade de São Paulo: Núcleo de Estudos da Violência, 2007.

PUGLIUCA, José Carlos Gobis. Direitos humanos. 1. ed. São Paulo: Rideel, 2010.

ROUSSEAU, J.J. Do contrato social. Tradução: Rolando Roque da Silva. Ridendo Castigat Mores: 2001. Disponível em: 〈http://www.ebooksbrasil.org/adobeebook/contratosocial.pdf>. Acesso: 06. fev. 2017.

SANTOS. Boaventura de Sousa. Prefácio do volume 1 - Democratizar a democracia: os caminhos da democracia participativa/ Boaventura de Sousa Santos, (Orgs). Rio de Janeiro: Civilização Brasileira, 2003.

SARLET. Ingo Wolfgang. A eficácia dos direitos fundamentais na perspectiva constitucional. 11. ed. rev. e atual. Porto Alegre: Livraria do Advogado, 2012. 
STRECK, Lenio Luiz; MORAIS, José Luis Bolzan de. Ciência política e teoria do estado. 8. ed. rev. e atual. Porto Alegre: Livraria do Advogado Editora, 2014.

TOURAINE, Alain. Um novo paradigma: para compreender o mundo de hoje. Tradução de gentil Avelino Titton. Petrópolis: Vozes, 2006. 